
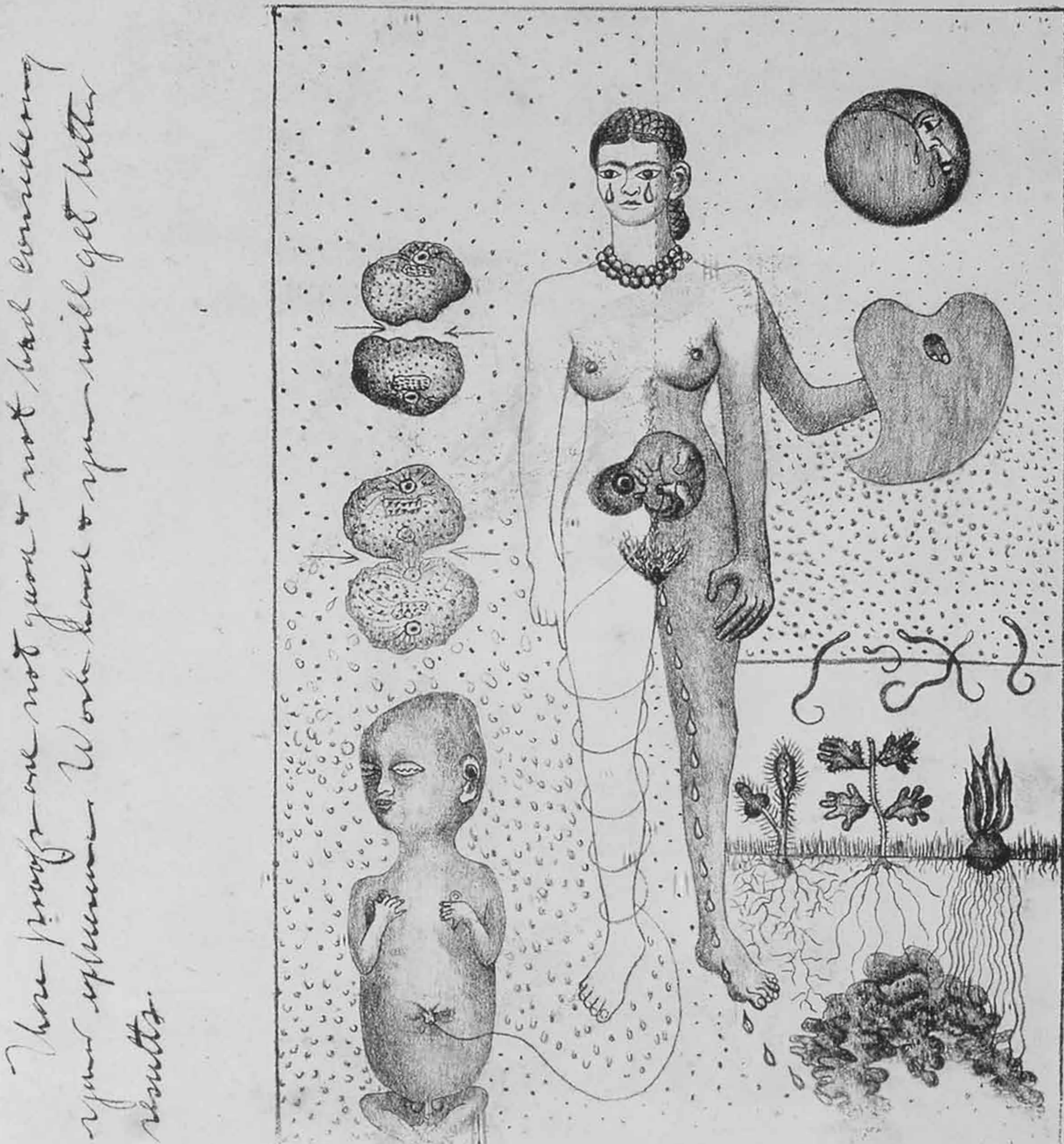


\section{Perda e Luto Fetal}

\section{Vera Ramos ${ }^{2}$ \\ Guilherme Rui Canta ${ }^{3}$}

1

Uma versão preliminar deste artigo foi apresentada sob a forma de conferência no VII Encontro Ser Bebé - «Vida Pré-Natal e Saúde Mental na Primeira Infância», realizado em 7 de dezembro de 2018 na Faculdade de Psicologia e Ciências da Educação da Universidade de Lisboa.

\section{2}

Psicóloga clínica, Membro Candidata da Sociedade Portuguesa de Psicanálise, Unidade de Psiquiatria da Infância e da Adolescência, Serviço de Pediatria do Hospital Garcia de Orta (HGO). E-mail:

verasantosramos@hotmail.com

\section{3}

Psicólogo clínico, Membro Candidato da Sociedade Portuguesa de Psicanálise, Hospital de Dia do Centro Hospitalar Psiquiátrico de Lisboa (CHPL). E-mail: guilhermeruicanta@gmail.com

\section{RESUMO}

Neste artigo, procuramos refletir sobre a abordagem clínica desenvolvida na consulta de Psicologia Clínica no Centro de Diagnóstico Pré-Natal do Serviço de Ginecologia e Obstetrícia do Hospital Garcia de Orta (HGO). Este trabalho clínico decorreu junto de futuras mães ou casais cujo processo gravídico normal se viu interferido pela súbita notícia de um grave problema com o feto e o consequente risco ou eventual desenlace de perda fetal. Assim, nesse contexto, o trabalho psicoterapêutico decorre debaixo de angústias intensas e avassaladoras derivadas de experiências afetivas associadas à morte. Não podemos deixar de salientar o paradoxo e o contrassenso inerentes ao facto de trabalharmos num serviço que gera vida e prepara para o nascimento de um bebé e simultaneamente estarmos próximo de fantasias e angústias de morte, felizmente apenas algumas tornadas reais, mas que constantemente invadem e estão latentes na mente dos pais e de toda a equipa envolvida nesta consulta.

\section{INTRODUC̣ÃO}

Frida Kahlo, pintora mexicana, representou de modo pungente e marcante o seu episódio de perda fetal, aquando da sua presença nos Estados Unidos da América, acompanhando os trabalhos do marido e também pintor Diego Rivera. Este período, anterior aos 25 anos, fora marcado por um sentimento de alienação e depressão, fruto da distância do seu país de origem, e pelo isolamento relacional. Frida temia não ser capaz de suportar o parto, estando as suas fantasias associadas aos seus problemas físicos resultantes da poliomielite de que havia padecido em criança e das profundas mazelas decorrentes de um anterior acidente de autocarro, que lhe deixou cicatrizes profundas, quer físicas, quer psíquicas. Até esse momento, a carreira artística de Frida era muito discreta e residia na sombra do marido, mas, curiosamente, após essa traumática experiência de perda, a sua produção encontrou um outro desenvolvimento e posterior reconhecimento no meio artístico. Nesse sentido, podemos especular que a arte serviu de forma de expressão de uma violenta angústia, mas também de veículo de sublimação do sofrimento. Numa carta escrita ao seu médico pessoal, Frida resume em poucas palavras um sofrimento dificilmente narrável: «Chorei bastante, mas acabou, não há mais nada que possa ser feito, excepto suportar.» (Bauer, 2007)

Assim, seremos acompanhados por algumas imagens de Frida Kahlo, cuja representação da perda encontra paralelismo no sofrimento psíquico das duas pacientes cujos casos clínicos passaremos a apresentar.

\section{PRIMEIRO CASO CLÍNICO}

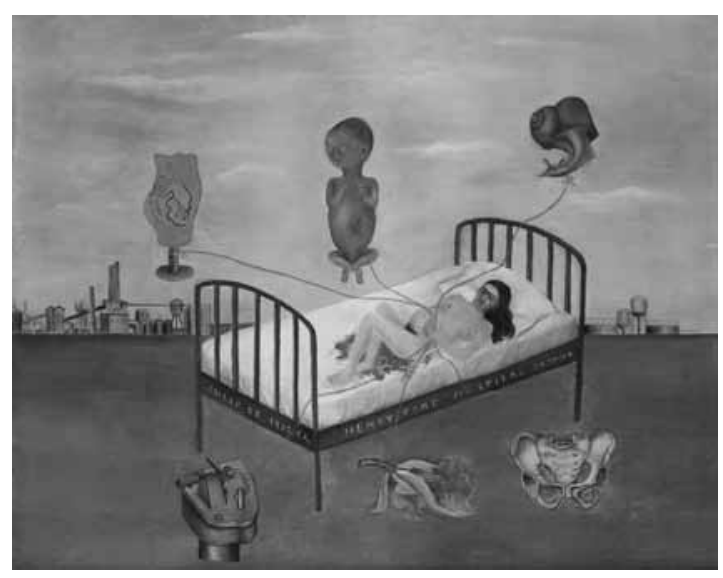

Henry Ford Hospital (1932), Frida Kahlo 
Vamos observar a psicoterapia com Inês, nome fictício escolhido para preservar a identidade real da paciente. $\mathrm{O}$ primeiro contacto aconteceu por referenciação do serviço de internamento de obstetrícia. Na sinalização, pediam a observação de uma paciente de 36 anos com perda fetal às 19 semanas. Tratava-se, segundo descrito no pedido de consulta, de uma gravidez gemelar interrompida no início da gravidez, devido ao diagnóstico de má formação do feto do sexo feminino, com indicação médica para feticídio seletivo.

Na sequência deste procedimento, ocorreu um aborto involuntário que originou também a perda do feto do sexo masculino. No pedido, era ainda referida a história anterior de cinco fertilizações in vitro, sem nenhuma prosseguir até ao final, e sem serem detalhados pormenores.

O primeiro contacto com Inês aconteceu em julho de 2013, poucos dias depois da sua perda e ainda internada. Encontrámo-la na companhia da mãe; dirigimo-nos a ambas, embora a Inês não nos tenha respondido. Aparentava não perceber o que lhe era dito, parecendo estar assustada, em choque e incapaz de falar. Foi a mãe que assumiu falar por Inês, dizendo comovida que a filha precisava da nossa ajuda. Precipitou-se ao tentar esclarecer-nos sobre o sucedido e foi bruscamente interrompida por nós, pois sob o ponto de vista contratransferencial identificámo-nos e tivemos empatia com o desespero da perda vivida por esta mulher. Assim, sentimos a insuportabilidade que seria para Inês ouvir ou pensar acerca do seu sofrimento. Apressámo-nos a terminar este nosso primeiro contacto, sentindo-o como ainda prematuro, pois parecia ser fonte de desconforto e ansiedade para Inês. Contudo, não sem antes lhe deixar a possibilidade de um novo encontro. Este primeiro contacto, vivido sob o signo do retraimento, ficou marcado pela impossibilidade de Inês de exprimir o que sentia, de dar nome ao seu afeto, ou sequer de o representar a palavra não dita, mas preenchida por uma angústia de tal modo intensa que parecia paralisar-lhe o pensamento. Perante a dor insuportável da perda, Inês vivia internamente o seu sofrimento num movimento que nos parecia possuir a qualidade de um retraimento esquizoide. Foi através da análise da contratransferência que acedemos ao sofrimento vivido internamente por esta paciente, que, no entanto, era incapaz de falar. Terminámos este primeiro encontro com algumas inquietações: Estaria Inês consciente do seu estado psicológico? Estaria ela disponivel para fazer um acompanhamento psicoterapêutico?

Tinham passado 15 dias desde a nossa primeira consulta quando encontrámos novamente Inês. Vinha acompanhada pelo marido, respondendo à possibilidade criada por nós de ambos os membros do casal poderem comparecer nessa consulta.
No entanto, importa ressalvar que são muito pontuais as vindas do marido à consulta, facto que no decurso do processo terapêutico nos ajuda a definir aquele como um espaço terapêutico para Inês.

Inês apresentava-se com uma postura corporal rígida, movimentando-se em bloco e ligeiramente curvada e parecendo carregar dentro de si o peso de toda a sua dor psíquica. Evitava o olhar, retraindo-se no seu silêncio, fechando-se no seu mundo interno, desencadeando contratransferencialmente em nós a necessidade de a proteger e de respeitar o seu isolamento. A presença do marido, tal como havia sido a da mãe, parecia surgir da necessidade de introduzir um terceiro. Um terceiro que, segundo palavras do marido, fosse o porta-voz. Acrescentamos, porta-voz do que não é dito, do que é difícil de sentir, representar ou sequer narrar, ou seja, porta-voz da história das suas perdas, e terceiro, no sentido da triangulação edipiana, que vem possibilitar a ligação ao desconhecido, ao técnico desconhecido, mas também ao que ainda é desconhecido para Inês do seu sofrimento e da sua história e com o qual ainda é difícil contactar. Pela voz do marido, pudemos conhecer a história das perdas deste casal: qualquer gravidez resultou de um processo de fertilização in vitro, sendo que as duas primeiras foram anembrionárias, nas duas seguintes o tratamento foi inviável e esta última foi interrompida às 19 semanas, tal como já mencionado.

Foi acordado com a paciente o início de um processo terapêutico após o regresso de férias. Nesse regresso, Inês contou-nos que tomou a decisão de ir trabalhar para fora, a uma longa distância, superior a duas horas de viagem, o que a levou a residir longe de casa durante a semana. Ficámos surpreendidos com essa notícia da paciente, pois anteriormente pareceu-nos haver uma significativa dependência (do marido e da mãe). Questionámo-nos se este seria um movimento de verdadeira autonomia perante o marido ou se, por outro lado, seria um maior isolamento e retraimento sobre si própria. Seria este um modo de realizar o luto distanciando-se ou, por outro lado, a distância consistiria num mecanismo de negação (omnipotente) da perda?

O desenvolvimento do processo psicoterapêutico traria algumas respostas para estas e outras questões. De seguida, iremos fornecer um breve resumo destes anos de acompanhamento.

Um aspeto que nos parece central no seu funcionamento, e que a acompanhará ao longo de toda a psicoterapia, é o desejo de um filho biológico, tendo chegado no início do nosso processo a submeter-se a nova fertilização in vitro, que novamente foi inviável, suscitando contratransferencialmente a dúvida de se este movimento seria ainda prematuro e baseado no desejo de recuperar os bebés perdidos ou o desejo 
real de gerar um filho saudável num corpo fértil - ou seja, seria esta uma repetição de algum modo patológica ou seria um desenvolvimento e evolução geradora? Neste sentido, levantámos a hipótese de a distância a que se propunha estar da família ser a possibilidade de gerar por ela própria e para ela própria um bebé, constituindo o outro uma espécie de ameaça. Sentíamos desde o início nesta mulher uma curiosa antinomia entre uma omnipotência resultante desta fantasia de se bastar a si própria e, por outro lado, uma necessidade de depender do outro. A sua comunicação sempre foi pouco expressiva e factual, mas percebíamos que muito ocorria na sua fantasia, sendo-nos isto comunicado pela dinâmica transferencial-contratransferencial, através de conteúdos de uma natureza esquizoide e por vezes até de um nível autístico - baseado sobretudo numa sensorialidade e permanecendo num domínio que Thomas Ogden (1992) designa por "Posição Autístico-Contígua», que no seu modo de funcionamento patológico vai aprisionar de maneira tirânica o psiquismo numa forma rígida, assimbólica e centrada nas sensações.

Foi possível ao longo da psicoterapia reconstituir as perdas que provocaram sofrimento em Inês, mencionando primeiro aquela temporalmente mais próxima, a morte do avô, que ocorreu um pouco antes de começar a tentar engravidar, e relacionando o sofrimento causado por esse acontecimento. Progressivamente, relacionou as perdas atuais com uma que ocorreu na infância: aos seis anos, o pai foi trabalhar para o estrangeiro, onde permaneceu até aos 12 anos de Inês. Esta situação constituiu um trauma, tendo Inês procurado ajuda psicológica e sentido uma mudança profunda na sua personalidade, que descreveu do seguinte modo: «Acho que passei a ficar no meu canto, calada, porque ainda hoje faço isso. Lá naquele sítio sinto-me segura, como se conseguisse deixar o mundo de fora e ali não acontecesse nada, nem bem, nem mal. Acho que primeiro tenho de resolver as coisas comigo e só depois deixar os outros entrarem.» Mais uma vez, surgiu o retraimento, uma postura omnipotente como modo de ocultar a falha, recorrendo a uma espécie de carapaça rígida para se proteger da dor gerada pela experiência, um isolamento autístico como forma de se proteger da realidade potencialmente nociva, fechando-se num mundo sensorial rigidificado, mas organizador de uma forma primitiva de existência.

$\mathrm{Na}$ sequência de um novo tratamento falhado, existiu no processo psicoterapêutico a possibilidade de entrar em contacto com aspetos de natureza depressiva, relacionados com a fantasia em torno da ideia de um corpo doente, infértil, sendo a repetição de exames e procedimentos médicos sentida como uma profunda intrusão. Foi possível na psicoterapia relacionar essas experiências corporais com o seu vivido emocional, do qual se protegia, mas que progressivamente foi sendo trazido para o discurso. Assim, Inês foi capaz de estabelecer ligações entre estas experiências e sentimentos de perda e incapacidade. Numa sessão em que descreveu a tristeza pela forma pragmática com que o marido enfrentava um novo e último tratamento de fertilidade que realizavam, salientou, e passamos a citar: «Vai chegar uma altura em que eu também, tal como ele, vou estar receosa, porque há uma parte do tratamento que é mais doloroso, que é tirar os ovários. Ai que disparate, os óvulos. Mas parece que estão a tirar qualquer coisa de dentro de mim.» Este curioso lapso revelou a forma como sentia um procedimento destinado a promover a gravidez como uma intrusão e roubo de uma parte corporal. Este exemplo também demonstra como coexistiam na mente de Inês uma vontade consciente de ter um filho e simultaneamente uma profunda e persistente fantasia inconsciente de perda, sendo esta uma perda de uma parte sua e igualmente da capacidade de gerar.

Parecia existir, e deixo esta ideia para reflexão, uma fantasia de que gerar um bebé poderia ser sujeitar-se a perder uma parte do seu corpo e de si própria, ou seja, mais do que somar uma nova existência à sua, implicava subtrair a sua existência para poder gerar alguém de novo. Mais do que uma qualquer limitação biológica em engravidar ou progredir nessa gravidez, parecia existir uma intensa fantasia que a impedia de gerar. A consciência destas fantasias que emergiram no decurso da psicoterapia ainda provocam uma elevada angústia, pelo que o processo continua a decorrer

\section{SEGUNDO CASO CLÍNICO}

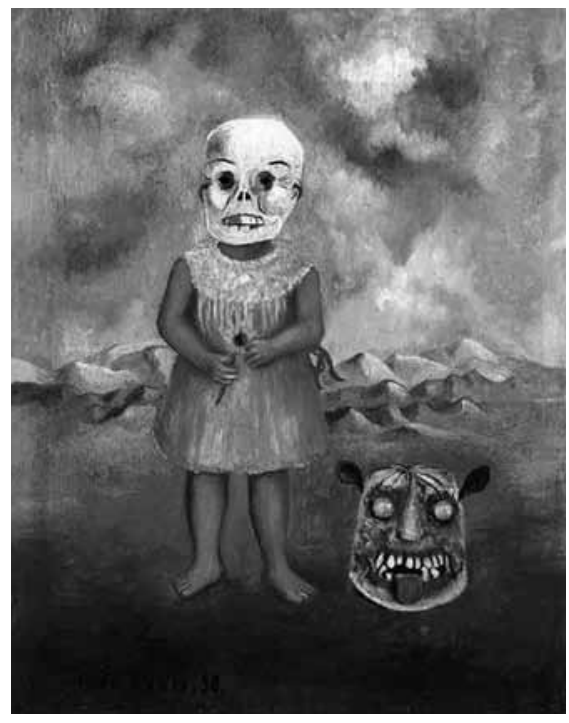

Girl with Death Mask (1938), Frida Kahlo

Maria, nome fictício escolhido para preservar a sua identidade, tinha 28 anos quando a conhecemos. Foi sinalizada através da reunião 
multidisciplinar do centro de diagnóstico pré-natal. Estava grávida de 17 semanas quando foi diagnosticada uma má formação fetal e admitida para IMG (Interrupção Médica da Gravidez).

A primeira consulta aconteceu uma semana depois da interrupção da gravidez, em abril de 2015. Maria tem uma aparência muito jovem, parecendo ainda mais nova do que a sua idade indicara, estatura baixa e aspeto magro, mas com postura ágil, uma atitude decidida e contacto agradável. Vem sozinha à consulta. Quando a recebemos na sala de espera e com poucas palavras ainda trocadas, ficamos de imediato inquietas com a postura aparentemente enérgica daquela jovem, que contrasta com a expectativa do que íamos encontrar, e pensamos no que Maria procurava negar ou evitava mostrar-nos. Apresentou-se dizendo: «trabalho na área da saúde». Pareceu-nos, do ponto de vista contratransferencial, que a paciente prefere apresentar-se de um modo profissional, como que procurando adotar uma posição de técnico, evitando falar da sua perda e fragilidade emocional. Simultaneamente, existe uma clivagem entre o afeto e a representação do evento traumático, que parece impedir o contacto com o afeto depressivo e por consequência bloquear a vivência do luto. De seguida e mantendo a lógica pragmática, diz-nos que fazia ecografias a si própria por curiosidade, para ver como estava o bebé, nas suas palavras: «fazia-o para ver o crescimento do feto». Primeiramente, Maria fala com espanto do que sucedera, da dificuldade em integrar internamente a gravidez, e, por isso, centra-se na descrição da dor física e do abandono que sentiu, primeiro por parte da equipa médica e posteriormente por parte do marido. Conforme a entrevista avançou, conseguiu diminuir as defesas e comunicar a sua experiência pessoal: «A primeira fase é a destruição de um sonho; a segunda fase é a parte física, a perda da barriga e o perceber que afinal já sentia o bebé mexer; e na terceira fase são as saudades do ser que não conheci.» Contou-nos que não foi uma gravidez planeada, tendo pensado anteriormente em abortar devido a restrições financeiras. Maria falou-nos da sua ambivalência inicial e da dificuldade em construir um espaço mental que preparasse a vinda deste bebé.

Nos primeiros momentos da terapia, que iniciámos, era difícil perceber quando Maria falava dela própria, do bebé ou da sua parte mais infantil, existindo claramente um investimento narcísico deste bebé, que era visto como um prolongamento dela própria. Um exemplo representativo disto é o discurso acerca das "saudades de estar grávida», manifestando uma perda dessa experiência para si própria e não se confrontando com a perda desse bebé, embora exista igualmente um medo de esquecer esse bebé, talvez por estar pouco representado no seu mundo interno.
Progressivamente, Maria foi falando de episódios em que imaginava esse bebé perdido, de situações da dinâmica familiar em que o marido ou os pais também conseguiam falar dessa perda, surgindo associado, primeiro, o sentimento de zanga perante a perda e, gradualmente, começando a emergir a tristeza de «não poder embalá-lo». Este período de qualidade depressiva vai permitir uma mais vasta representação psíquica do bebé: a representação da perda deste bebé e da forma como a paciente foi vivendo a situação no plano emocional. Aliás, é um período muito produtivo e evolutivo da terapia, em que Maria abandonou as anteriores defesas pela intelectualização e racionalização e contactou com o sentimento depressivo.

Este período, embora marcado por emoções difíceis de vivenciar, foi extremamente importante para a evolução clínica da paciente, existindo uma vincada mudança no discurso e na capacidade de pensar em si própria e nas suas experiências de vida, nomeadamente a então recente vivência traumática. Neste processo, também abandonou o modo mais narcísico, descrevendo uma maior capacidade de pensar no outro e investir esse outro de um modo objetal.

Nesse período, relata o seguinte sonho, que consideramos muito relevante: «Sonhei com um bebé que tinha seis meses, era mulato. Era o meu bebé, tinha carapinha e boné. $\mathrm{O}$ cabelo dele não crescia na zona onde está o boné. Eu chorava e era como se ele tivesse estado o tempo todo no hospital, e era a sensação de ter recuperado o meu bebé, mas ao mesmo tempo de o ter abandonado. O meu pai estava comigo.» $\mathrm{Na}$ sequência deste sonho, refere que a sua mãe está a passar por um período de enorme tristeza e que se sente sozinha, passando os dias a sonhar. Ainda na mesma sessão, Maria revela que decidiu sair de casa e que, por identificação à mãe, não queria viver do mesmo modo. Pensamos que este sonho é revelador do estado depressivo reativado pela perda do bebé e pela reatualização, a propósito deste evento traumático, do conflito edipiano. Através da perda do bebé, Maria revisitou o seu Édipo, numa narrativa permeada pelo sentimento de culpa e associado à fantasia de um bebé diferente e danificado. Este sonho parece condensar o bebé que perdera, associado a uma pulsão de morte, e, por identificação, ela transforma-se neste bebé, sentindo-se abandonada e simultaneamente abandonante. Esta sessão levantou algumas questões dentro de nós, nomeadamente se existiria uma atuação (acting out) na sua saída de casa, por existir uma afeto depressivo difícil de tolerar. Este período foi tumultuoso ao nível da sua relação com o marido, na qual projetava um sentimento de exclusão e abandono. No plano consciente, a paciente associou a saída de casa ao facto de o marido não ter fornecido o apoio que considerava 
necessário e de este não olhar para a perda do mesmo modo. Convém explicar que este é um segundo casamento para o marido, que já tem dois filhos da anterior relação. Na perceção de Maria, ele não terá vivido a perda do mesmo modo, pois já tem filhos, enquanto para ela seria uma nova vivência. Neste contexto, surgiu uma enorme zanga, podendo ser debatidos conflitos que anteriormente permaneciam ocultos no seio do casal.

Através da elaboração da agressividade desencadeada pela perda, foi possível ir efetuando um trabalho de luto. Simultaneamente, ocorreu uma progressiva aproximação ao marido, existindo longas conversas em que ele também revelou um sofrimento perante a perda, até então negado ou não vivido, havendo a possibilidade de repararem e reconstruirem os elos afetivos enquanto casal. $\mathrm{Na}$ sequência do reencontro amoroso, surgiram nas sessões um conjunto de sonhos, cujo denominador comum era o desejo de reconciliação com o marido, o sonho de um casamento até então não concretizado e o nascimento de um bebé.

Esses sonhos foram encontrando expressão na realidade externa: a paciente casou e atualmente tem um bebé com cerca de 16 meses.

\section{CONCLUSÃO}

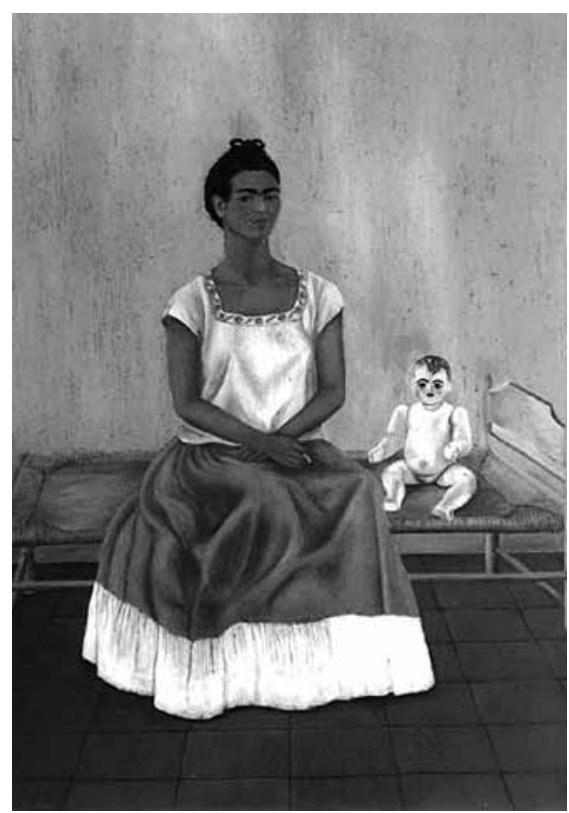

Me and My Doll (1937), Frida Kahlo

O luto é uma das experiências mais dolorosas da vida. Aqui, falámos de perda e morte de seres humanos fantasiados pelas mães e pais, que nunca chegaram a existir, que por alguma razão não puderam nascer. Assim, estamos perante um luto muito específico (Leon, 1990). Uma perda traumática em que não existe uma representação física do sujeito perdido e não houve uma relação concreta e continuada no tempo. O luto induz à regressão, ao confronto com a realidade, e ao mesmo tempo revela a dimensão narcísica dos investimentos objetais (Leon, 1990; Soubieux,
2013). Assim, o luto irá depender da relação objetal perdida e da natureza das ligações preexistentes à perda, mas convocará também os recursos utilizados para elaborar a perda original e o desenvolvimento da autonomia psíquica. Bowlby (1985/1973), nos seus trabalhos clássicos, demonstrou como a separação entre o bebé e a mãe opera como protótipo psíquico para a representação do luto, que vai sendo evocado ao longo da vida quando o adulto se confronta com perdas. Deste modo, a perda perinatal envolve um conjunto de complexidades: o feto não é conhecido, a gravidez é interrompida e os futuros pais são forçados a reatualizar as suas primeiras relações pais-criança.

O traumatismo provocado pelo luto induz a uma acentuada regressão, em que o sujeito incorpora o objeto perdido no $\mathrm{Eu}$, recorrendo ao mecanismo de identificação como forma de promover a permanência deste no seu interior e negando a própria realidade da perda (Soubieux, 2013). É fundamental perceber que a necessidade da mãe do seu bebé resulta do facto de esta ligação (Bonding) começar muito antes do nascimento e envolver elementos da sua autoimagem projetada na representação do bebé imaginário, mas perdido (Golse, 2006; Leon, 1990).

O processo de luto, tal como Freud (1915/1917) já tinha mencionado, envolve o reviver de memórias referentes ao falecido, aspeto que se revela complexo numa situação de perda fetal, onde o confronto com o bebé real não chegou a ocorrer. Aqui, o processo de luto vai envolver sobretudo a elaboração das fantasias associadas ao bebé na ausência deste mesmo. O processo de luto de uma perda perinatal é extremamente difícil, uma vez que existem pequenas ou intangíveis evidências da existência do bebé (Leon, 1990); implica a quebra do processo de parentalização e remete para uma perda intimamente ligada ao corpo da mãe e deste modo ao materno e ao feminino (Soubieux, 2013). A situação de gravidez em si mesma já induz a uma regressão a fases primárias do desenvolvimento, mas a perda de um bebé convoca conflitos intrapsíquicos não resolvidos associados à relação de objeto primário (Leon, 1990). Este aspeto fica bem evidente no primeiro caso clínico que apresentámos, em que a perda reatualiza a relação de marcada dependência com os objetos originários e os traumas infantis associados à separação. A perda do bebé vai adquirir um carácter melancólico, embora a representação sobre a forma de linguagem e material simbólico seja muito escassa e predomine um modo autístico-contíguo de encapsulamento da experiência emocional, que se manifesta através de queixas somáticas ou comportamentos, e por uma retirada da paciente para um refúgio psíquico (Ogden, 1992; Steiner, 1997).

Neste primeiro caso clínico, ficou ainda bem evidente que a morte perinatal é sentida como 
a perda de uma parte do self, onde literalmente uma parte da mãe morreu. Através da sua identificação infantil, Inês ligou-se à imagem dela própria como uma criança que não nasceu: aqui, o não nascimento significa um não nascimento psíquico e emocional. $\mathrm{O}$ recurso à identificação projetiva, como forma de anular a perda e separação, não permite a elaboração desta mesma, ficando deste modo a paciente aprisionada a uma ilusão (Apprey, 1987; Apprey \& Stein, 1993).

Durante a gravidez, também são revividos os aspetos relacionados com a situação edipiana, onde a futura mãe pode reviver os seus conflitos originais com a sua própria mãe (Leon, 1990), elemento que ficou em evidência no segundo caso clínico que apresentámos. Alguns autores salientaram que o conflito edipiano durante a gravidez poderá levar a mulher a temer pela sua vida ou a vida do bebé, e por consequência interpretará a perda ocorrida como um castigo pelos seus desejos edipianos proibidos (Leon, 1990). Maria viveu uma dupla punição: por um lado, a punição perante um bebé que não foi desejado, e por isso não antecipado na mente da mãe, não existindo um espaço mental para a sua representação, e, por outro, a punição pela reatualização da situação edipiana tal como convocada pela gravidez. A perda é vivida numa posição depressiva da experiência psíquica (Ogden, 1992), ativando um sentimento de culpa, mas também de zanga muito intensa. O trabalho psicoterapêutico visou diminuir esta zanga e permitir a recuperação de aspetos internos com valência positiva, fortalecendo a relação do casal e permitindo o reaparecimento do desejo de maternidade. No caso clínico, ficou bem evidente que a perda vem reatualizar conflitos intrapsíquicos respeitantes à relação amorosa, mas também relativos às relações com os objetos primários, sendo por isso fundamental uma elaboração psíquica desses conflitos, para que não se constituam como um entrave ao processo de luto.

Em síntese, podemos diferenciar os dois casos clínicos: o primeiro com um funcionamento mais arcaico e centrado em angústias do tipo autístico-contíguo, por vezes vividas ao nível somático ou comportamental e de difícil inscrição no discurso simbólico, bem como com uma reclusão em refúgios psíquicos de difícil acesso; o segundo com um funcionamento de nível depressivo e com uma vivência de tipo edipiano, mais marcado pelo conflito psíquico e agressividade relacional, possuindo uma maior capacidade de representação psíquica e inscrição narrativa.

Estas diferenças entre os casos apresentados permitem-nos também salientar que o processo psicoterapêutico terá diferenças assinaláveis. Se, por um lado, a necessidade de elaborar esta perda tão específica serve de elemento comum, por outro, percebemos que as diferenças de personalidade e de estrutura psíquica irão marcar uma especificidade no modo como o luto é vivido e como podemos potenciar a sua elaboração. Assim, a partir da discussão destes casos clínicos fica evidente que a natureza e o nível de conflito intrapsíquico serão determinantes cruciais para o significado pessoal e a forma como a perda irá resultar, bem como para os desafios que a psicoterapia poderá colocar (Leon, 1990; Salomonsson, 2018).

Pudemos discutir diversas formas de elaboração da perda, a começar pela reação melancólica presente no primeiro caso clínico e pela reação depressiva do segundo caso clínico, e gostaríamos de terminar com um exemplo de elaboração pela sublimação do sofrimento psíquico, que também temos visionado ao longo da apresentação através das imagens das obras de Frida Kahlo. A pintora, através da sua sublime expressão artística, procurou dar uma forma ao seu sentimento de perda, de estilhaçamento, de dor corporal e trauma emocional profundo, que, tendo surgido cedo na sua vida, se foi repetindo com as perdas perinatais. Gostaríamos então de finalizar com um último exemplo de sublimação doado pela nossa paciente Maria, sob a forma do seguinte poema:

$$
\begin{gathered}
\text { És aquele que não chegou a ser, } \\
\text { mas de ser para mim sempre foste. } \\
\text { És aquele que não chegou a ninguém, } \\
\text { mas de mim chegaste, de mim sentiste. } \\
\text { E há seres que nunca chegaram a ser, }
\end{gathered}
$$

mas serão eternizados no simples sentimento do amor.

$$
\text { E se para ser só é preciso sentir, }
$$

então serás meu para sempre, sem mas. 


\section{ABSTRACT}

In this article we seek to reflect on the clinical approach developed in the Clinical Psychology consultation at the Prenatal Diagnosis Center of the Gynecology and Obstetrics Service of Hospital Garcia d'Orta (HGO). This clinical work was carried out with future mothers or couples whose normal pregnancy process was interfered by the sudden news of a serious problem with the fetus and the consequent risk or eventual outcome of fetal loss. Thus, in this context, psychotherapeutic work takes place under intense and overwhelming anxieties derived from affective experiences associated with death. We cannot fail to point out the paradox and contradiction inherent in the fact that we work in a service that generates life and prepares for the birth of a baby and at the same time we are close to fantasies and death anxieties, fortunately only a few made real, but which constantly invaded and were latent in the mind of the parents and the entire team involved in this consultation.

KEYWORDS: mourning; fetal loss; pregnancy; psychotherapeutic support.

\section{BIBLIOGRAFIA}

Apprey, M. (1987). Projective Identification and Maternal Misconception in Disturbed Mothers. British Fournal of Psychotherapy, 4(1), 5-22.

Apprey, M. \& Stein, H. F. (1993). Intersubjectivity, Projective Identification and Otherness. Duquesne University Press.

Bauer, C. (2007). Frida Kahlo. Prestel Verlag.

Bowlby, J. (1985/1973). Apego e Perda, Volume 3 Perda, Tristeza e Depressão. Martins Fontes.

Freud, S. (1915/1917). Luto e Melancolia. Em Edição Standard Brasileira das Obras Psicológicas Completas de Sigmund Freud, Volume XIV, pp. 243-263. Imago.

Golse, B. (2006). O Ser-Bebé. Climepsi Editores.

Leon, I. G. (1990). When a Baby Dies Psychotherapy for Pregnancy and Newborn Loss. Yale University.

Ogden, T. (1992). The Primitive Edge of Experience. Karnac Books.

Salomonsson, B. (2018). Psychodynamic Interventions in Pregnancy and Infancy - Clinical and Theoretical Perspectives. Routledge.

Soubieux, M.-J. (2013). Le Berceau Vide - Deuil Périnatal et Travail du Psychanalyste. Éditions Érès.

Steiner, J. (1997). Refúgios Psíquicos - Organizações Patológicas em Pacientes Psicóticos, Neuróticos e Fronteiriços. Imago. 